\title{
Effect of clay content on soil stabilization with alkaline activation
}

\begin{abstract}
This paper presents the role of clay portion in soil used to stabilize soils during alkaline activation with potassium-based alkaline activator. A $10 \mathrm{M}$ potassium hydroxide solution was utilized to activate the soils with and without palm oil fuel ash (POFA) at a solution. Soils with and without POFA mixtures were tested using unconfined compression tests and microstructural analysis (using scanning electron microscopy and X-ray diffraction). Comparing the strength of the mixtures with and without POFA, the results presented that short-term compressive strength was higher for mixtures with POFA. However, after longer curing the admixtures of higher kaolinite content with POFA reached significantly higher strength levels than the admixtures without POFA. This work brings new insights to the soil stabilization by alkaline activation providing a relatively new avenue for effective utilization of aluminosilicate source materials with parent-treated soils. The clay minerals of hosted soil play an important role in soil stabilization with alkaline activation that affects the behavior of binder with hosted soil.
\end{abstract}

Keyword: Soil stabilization; Ground improvement; Alkaline activation; Geopolymerisation 